\title{
QUÍMICA MINERAL E IDADES U-Pb DE MONAZITAS DE PLACERS MARINHOS DA REGIÃO NORTE FLUMINENSE
}

\author{
Elizabeth Kerpe Oliveira ${ }^{1}$; Bernhard Bühn ${ }^{2}$; José Marques Correia Neves ${ }^{1}$; \\ Alexandre de Oliveira Chaves ${ }^{3}$; Mário Luiz de Sá Carneiro Chaves ${ }^{3}$ \\ 1. CDTN/CNEN, Belo Horizonte, MG, eko@cdtn.br; $1^{*}$ In memoriam. \\ 2. Laboratorio de Geocronologia,Universidade de Brasília, Brasília, DF, berbu@unb.br \\ 3. CPMTC-IGC-UFMG, Belo Horizonte,MG, alochaves@yahoo.com.br; mchaves@ufmg.br \\ Recebido em 14 de setembro de 2012; aceito em 25 de fevereiro de 2013
}

RESUMO: Este trabalho abrange o estudo de química mineral e geocronologia U-Pb de grãos de monazita, composicionalmente homogêneos, provenientes de várias jazidas explotadas pelas Indústrias Nucleares do Brasil (INB) em placers marinhos da região de Buena, litoral norte fluminense. A área está localizada na região da Bacia de Campos e, geologicamente, pertence à Província Tectônica Mantiqueira, que representa um sistema orogênico neoproterozóico desenvolvido na borda sudeste do Cráton São Francisco. As idades U$\mathrm{Pb}$ obtidas por LA-ICP-MS abrangem um intervalo entre $486 \mathrm{Ma}$ e $579 \mathrm{Ma}$, sendo que as idades mais jovens são de grãos de monazitas ricos em cério. Por outro lado, as idades mais antigas correspondem a grãos de monazitas com tendência à composição cheralítica, nos quais ocorre um enriquecimento principalmente em $\mathrm{CaO}$ e $\mathrm{ThO}_{2}$. A comparação dessas idades com informações geológicas regionais permite inferir as suítes G2 (granitos granada-biotita gnaisse foliado) e G3 (leucogranitos, não deformados, encaixados em G2) como rochas-fonte da população de monazita mais antiga, suítes estas relacionadas com o arco sin-colisional desenvolvido simultaneamente ao metamorfismo e à deformação regional Neoproterozóica. Já a população de monazita mais jovem pode ser proveniente de corpos graníticos das suítes G4 (plútons magmáticos zonados) e G5 (ballons magmáticos), representantes das fases pós-colisionais.

Palavras-chave: Monazita, quimica mineral, idades U-Pb, LA-ICP-MS.

ABSTRACT: MINERAL CHEMISTRY AND U-Pb AGES OF MONAZITE FROM MARINE PLACERS OF THE NORTHERN RIO DE JANEIRO STATE - This research focusses on mineral chemistry and $\mathrm{U}-\mathrm{Pb}$ geochronology of monazite grains of homogeneous composition, originating from several marine-placer deposits exploited by Indústrias Nucleares do Brasil (INB), in Buena, northern Rio de Janeiro State. Buena is located close to the Campos Basin and related to the geological context of the Mantiqueira Tectonic Province, which represents a neoproterozoic orogenic system developed in the southern edge of the São Francisco Craton. Uranium-Pb ages by LA-ICP-MS fall between $486 \mathrm{Ma}$ and $579 \mathrm{Ma}$ Younger ages are related to Ce-rich monazite. Older ages correspond to monazite with cheralitic signature, chiefly enriched in CaO and $\mathrm{ThO}_{2}$. These ages are interpreted in the geological context of the Mantiqueira Tectonic Province as rock sources for older monazites, which are correlated to syn-collisional arc simultaneously developed together the neoproterozoic regional metamorphism and deformation. The younger monazites came from granitic plutons of G4 and G5 suites, related to post-collisional phases.

Keywords: Monazite, mineral chemistry, U-Pb ages, LA-ICP-MS.

\section{INTRODUÇÃO}

Monazita, um grupo de fosfato rico em elementos de terras raras leves (ETRL), apresenta-se como fase mineral acessória, comumente disseminada em diversos litotipos (ígneos, metamórficos e sedimentares). Diferentes abundâncias dos ETRL e tório são responsáveis pela composição extremamente variada de monazita, refletindo não só condições de cristalização como também transformações que a rocha hospedeira sofreu ao longo do tempo geológico (Williams et al., 2007).

$\mathrm{Na}$ solução sólida monazita-cheralita ocorrem composições intermediárias que se tornam cada vez mais ricas em Ca e Th em direção ao membro puro denominado cheralita [CaTh $\left(\mathrm{PO}_{4}\right)_{2}$ ] e mais ricas em terras raras na direção da monazita [2REEPO $\left.{ }_{4}\right]$ (Linthout, 2007).

Este trabalho tem por objetivo investigar a relação da composição obtida via microssonda eletrônica com idades U-Pb via LA-ICP-MS (laserablation inductively coupled plasma-mass spectrometry), em grãos de monazita de depósitos marinhos de minerais pesados (paleopraias) localizados ao longo da região costeira de Buena no litoral norte-fluminense, e indicar possíveis rochas fontes para as populações de monazita

\section{CONTEXTO GEOLÓGICO}

Buena está localizada na região da Bacia de Campos (Figura 1), cujo embasamento é composto por rochas gnáissicas paraderivadas e granitognaisse de alto grau. Esta bacia se estende do sul do Espírito Santo ao Estado do Rio de Janeiro e, geologicamente, pertence à Província Tectônica Mantiqueira, que apresenta um sistema orogênico neoproterozóico desenvolvido na borda sudeste do Cráton São Francisco durante a Orogênese Brasiliana-Pan-Africana (650-490 Ma) e inclui parte dos orógenos Ribeira e Araçuaí (Pedrosa-Soares et al., 2007). 


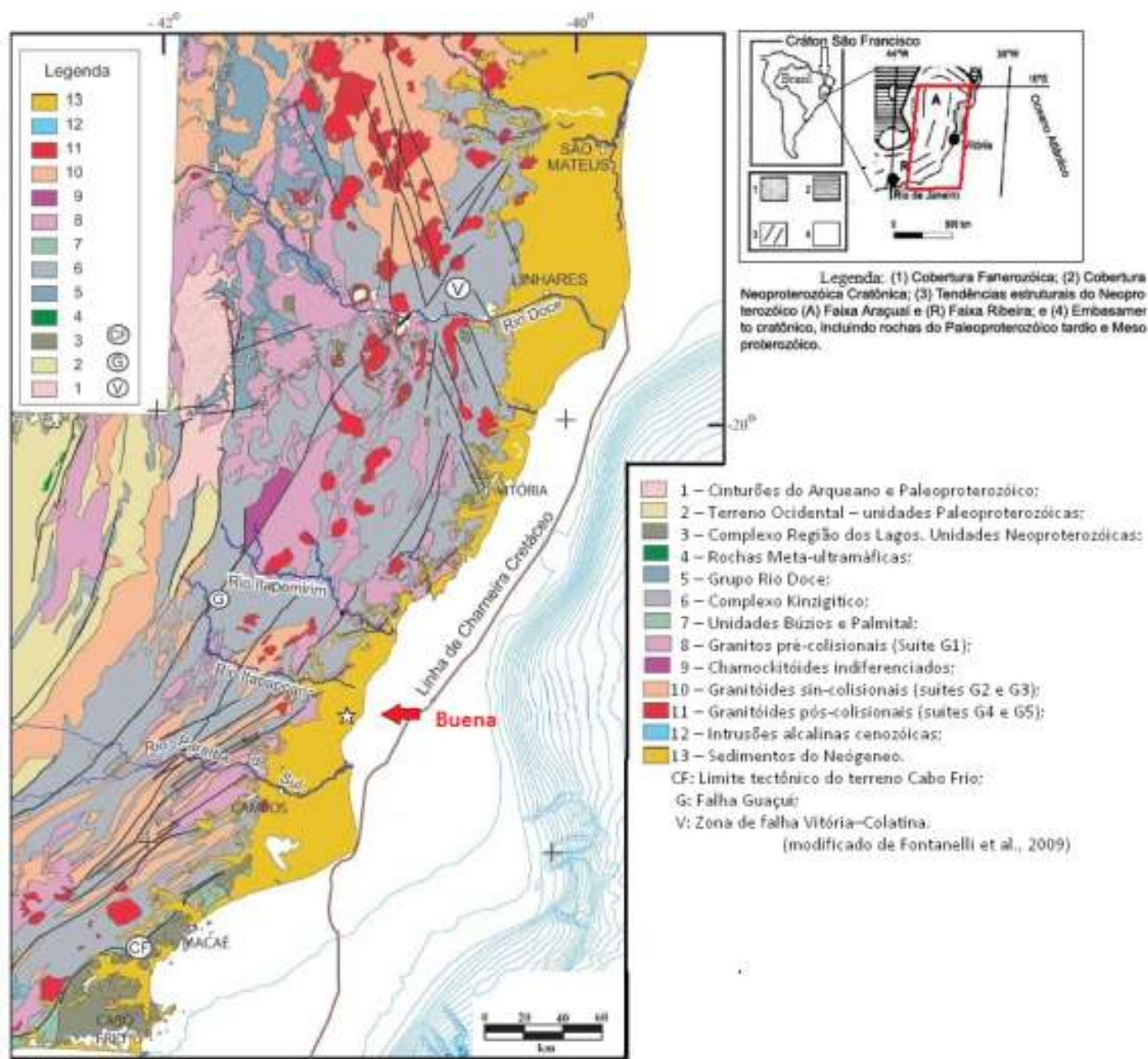

Figura 1 - Geologia dos Estados do Espírito Santo, parte do Rio de Janeiro e de Minas Gerais. 1 - Cinturões do Arqueano e Paleoproterozóico; 2 - Terreno Ocidental - unidades Paleoproterozóicas; 3 - Complexo Região dos Lagos. Unidades Neoproterozóicas: 4 Rochas Meta-ultramáficas; 5 - Grupo Rio Doce; 6-Complexo Kinzigítico; 7 - Unidades Búzios e Palmital; 8 - Granitos pré-colisionais (Suíte G1); 9 - Charnockitóides indiferenciados; 10 - Granitóides sin-colisionais (suítes G2 e G3); 11 - Granitóides pós-colisionais (suítes G4 e G5); 12 - Intrusões alcalinas cenozóicas; 13 - Sedimentos do Neógeneo. CF: Limite tectônico do terreno Cabo Frio; G: Falha Guaçuí; V: Zona de falha Vitória-Colatina (modificado de Fontanelli et al., 2009).

Esses orógenos são estruturados em domínios externo e interno, sendo o primeiro localizado mais a oeste e composto por embasamento antigo (>1,8 Ga). O domínio interno, mais a leste, encontra-se adjacente à bacia. É constituído por uma extensa unidade nomeada "Complexo Kinzigítico", que é composto por rochas paragnáissicas aluminosas como cordierita-granadabiotita gnaisse, granada-biotita gnaisse e biotita gnaisse com lentes de mármore, grafita, quartzito, rochas cálcio-silicáticas paraderivadas e rochas ortoanfibolíticas. Próximo à costa, as rochas paragnaíssicas tornam-se mais ricas em alumínio, i.e. como grafita-sillimanita-cordierita-granada-biotita gnaisse e, apresenta, em menor quantidade, granulito charno-enderbítico. As rochas foram submetidas a processos de metamorfismo que variam de fácies anfibolito alto a granulito, sendo comum a fusão parcial sob diferentes graus de anatexia. Ainda no domínio interno, aloja-se o Grupo
Rio Doce, que é composto por meta-grauvaca, estaurolita-granada-mica xisto, quartzito e rochas gnáissicas bandadas fácies xisto-verde a anfibolito. 0 domínio interno representa arcos magmáticos pré- e sin-colisionais e vários plútons tardi- a póscolisionais (Pedrosa-Soares et al., 2007).

O arco continental pré-colisional é formado por rochas gnáissicas granodioríticas tipo-I e tonalíticas, genericamente denominadas de suíte G1. O arco sincolisional desenvolvido, concomitante ao metamorfismo e deformação regionais, é representado por granada-biotita gnaisse foliado (suite G2), que contêm minerais acessórios ricos em alumínio e restos de paragnaisse bandado e migmatito (Pedrosa-Soares et al., 2007).

A suite G2 deu origem a leucogranito tipo-S tardi-colisional que caracteriza a suíte G3, tipo-I, formada por corpos graníticos a granodioríticos que intrudiram ao longo de zonas de cisalhamento. 
Corpos graníticos com domínios pegmatíticos ricos em turmalina (suite G4) e plútons graníticos sem foliação (suite G5), ora zonados com gabro no núcleo e granito nas bordas, representam magmatismo pós-colisional. A suite G5 tem ocorrência mais ampla que a suíte $\mathrm{G} 4$.

Em termos regionais, o pico do metamorfismo ocorreu durante a fase sin-colisional, entre 590$550 \mathrm{Ma}$, associado à deformação principal que gerou a foliação regional das diversas litologias (Pedrosa-Soares et al., 2007).

Ao longo da faixa litorânea brasileira compreendida entre o delta do Rio Paraíba do Sul, RJ, até a região de Porto Seguro, BA, ocorrem, no sentido interior-praia, rochas pré-cambrianas do embasamento cristalino, rochas sedimentares terciárias e depósitos recentes relacionados aos cordões arenosos de praias ou cristas praiais (Suguio, 1998), alongados na direção NE-SW e posicionados paralelos à linha de praia atual (Martin et al., 1997). Os cordões litorâneos que abrigam a mineralização de minerais pesados da região, estendem-se continuamente por cerca de $18 \mathrm{~km}$, paralelo à linha de praia, variando sua largura de 50 a 100 metros e sobressaindo-se no relevo até uma cota máxima de 7 metros, ora afastando-se, ora aproximando-se da linha de praia atual (Martin, 1997). Os principais minerais pesados de interesse econômico associados a esses cordões arenosos litorâneos, em paleodunas, foram mineralogicamente caracterizados por Kerpe (2003).

\section{METODOLOGIA}

Os grãos de monazita investigados nesta pesquisa foram coletados em um concentrado final constituído pelo produto da lavra de várias jazidas de placers marinhos explotadas pelas Indústrias Nucleares do Brasil (INB) na região de Buena (Figura 1), litoral norte fluminense, município de São Francisco de Itabapoana, RJ.

Uma amostra do concentrado puro de monazita (grãos desagregados) com 20 quilos foi reduzida, em sucessivas etapas de homogeneização e quarteamento, visando separar alíquotas representativas com cerca de 3 gramas, nas quais grãos individualizados selecionados foram montados em lâminas delgadas e blocos de resina, submetidos ao desbaste e polimento até se obter uma superfície com qualidade adequada para petrografia e análises quantitativas na microssonda eletrônica. O estudo das características microscópicas da monazita, em lupa e microscópio óptico petrográfico polarizador, com luz transmitida e refletida, foi realizado no Laboratório de Inclusões Fluídas e Metalogênese, CDTN/CNEN.
Composições químicas de monazita foram obtidas na Universidade Federal de Minas Gerais, em uma microssonda JEOL, modelo JXA-8900, através de espectrometria por dispersão de comprimento de onda (WDS). As condições analíticas seguiram o procedimento de Vlach (2010), que estabeleceu como parâmetros instrumentais $300 \mathrm{nA}$ de intensidade da corrente de feixe, $15 \mathrm{kV}$ de tensão de aceleração e $1 \mu \mathrm{m}$ para o diâmetro do feixe.

Os elementos e seus respectivos materiais de referência (Smithsonian Institution, Jarosewich, 2002) utilizados foram $\mathrm{Al}_{2} \mathrm{O}_{3}$ (YAG), $\cup_{2}\left(\mathrm{UO}_{2}\right), \mathrm{CaO}$ $\left(\mathrm{Ca}_{2} \mathrm{P}_{2} \mathrm{O}\right), \mathrm{SiO}_{2}\left(\mathrm{ThSiO}_{4}\right), \mathrm{ThO}_{2}\left(\mathrm{ThSiO}_{4}\right), \mathrm{YPO} 4(\mathrm{NMNH}$ 168499) $\mathrm{La}_{2} \mathrm{O}_{3}$ (NMNH 168490), $\mathrm{Y}_{2} \mathrm{O}_{3}$ (YAG), $\mathrm{PbO}$ (crocoita), $\mathrm{Ce}_{2} \mathrm{O}_{3}$ (NMNH 168484), $\mathrm{P}_{2} \mathrm{O}_{5} \quad\left(\mathrm{NdPO}_{4}\right)$, $\mathrm{Pr}_{2} \mathrm{O}_{3} \quad$ (NMNH 168493), $\quad \mathrm{Nd}_{2} \mathrm{O}_{3} \quad$ (NMNH 168492), $\mathrm{Sm}_{2} \mathrm{O}_{3}$ (NMNH 168494), $\mathrm{Fe}_{2} \mathrm{O}_{3}$ (hematita), $\mathrm{Gd}_{2} \mathrm{O}_{3}$ (NMNH 168488), $\mathrm{Dy}_{2} \mathrm{O}_{3}$ (NMNH168485).

Análises isotópicas in situ de U-Pb por LA-ICP-MS, segundo o procedimento analítico descrito em Bühn et al. (2009), foram realizadas no Laboratório de Geocronologia da Universidade de Brasília, utilizando o padrão GJ-1 de Jackson et al. (2004) como material de referência primária no esquema analítico standard-sample bracketing. Para cada grão de monazita foram obtidas quatro análises pontuais com diâmetros de aproximadamente $40 \mu \mathrm{m}$. A redução dos dados incluiu a consideração dos brancos, o cálculo dos erros 2 sigma do desvio padrão, e os valores theta $(\theta)$ conforme Albarède et al. (2004). Efetuou-se a correção para Pb comum utilizando os valores de Stacey \& Kramers (1975). Diagramas de concórdia U-Pb foram construídos com auxílio do software Isoplot (Ludwig, 2003).

\section{RESULTADOS}

\subsection{Morfologia / Microscopia óptica}

O estudo das características microscópicas da monazita em lupa e microscópio polarizador petrográfico, com luz transmitida e refletida, indicou o caráter arredondado da maioria dos grãos, geralmente límpidos ou levemente turvos, de cor amarelo claro.

\subsection{Química Mineral}

A composição química de seis grãos de monazita analisados por microssonda eletrônica está apresentada na Tabela 1. O ETRL mais abundante é o Ce (26-32\% de $\mathrm{Ce}_{2} \mathrm{O}_{3}$ em peso), o que caracteriza esses grãos como monazita-(Ce). O teor de Th e Ca é variável nos diferentes grãos. Também foram obtidas imagens por elétrons retroespalhados (Figuras 2a, 2b, 2c), as quais revelam um caráter composicional homogêneo em todos os grãos investigados. 
Tabela 1 - Composição química de grãos de monazitas de Buena por microssonda eletrônica

\begin{tabular}{|c|c|c|c|c|c|c|c|c|c|c|c|c|c|c|c|c|c|}
\hline $\begin{array}{c}\text { Amostra } \\
\text { (\% em peso) }\end{array}$ & Al2O3 & UO2 & $\mathrm{CaO}$ & $\mathrm{SiO2}$ & ThO2 & La2O3 & Y2O3 & Pbo & $\mathrm{Ce} 2 \mathrm{O3}$ & P2O5 & Pr203 & $\mathrm{Nd2O3}$ & $\mathrm{m} 2 \mathrm{O} 3$ & $\mathrm{FeO}$ & Gd2O3 & Dy203 & Total \\
\hline F2G1T-1 & 0.00 & 0.25 & 0.58 & 2.62 & 13.82 & 15.14 & 0.26 & 0.48 & 29.98 & 25.54 & 2.48 & 8.93 & 0.99 & 0.03 & 0.41 & 0.13 & 101.62 \\
\hline F2G1T-2 & 0.01 & 0.25 & 0.56 & 2.70 & 14.07 & 15.03 & 0.26 & 0.48 & 29.24 & 25.50 & 2.52 & 8.86 & 0.91 & 0.02 & 0.36 & 0.16 & 100.93 \\
\hline F2G1T-3 & 0.00 & 0.21 & 0.55 & 2.36 & 12.47 & 15.94 & 0.27 & 0.41 & 30.05 & 26.13 & 2.58 & 8.71 & 0.92 & 0.01 & 0.48 & 0.16 & 101.24 \\
\hline F3G1T-1 & 0.00 & 0.33 & 0.93 & 0.20 & 4.42 & 13.19 & 1.36 & 0.21 & 29.13 & 31.17 & 3.17 & 12.22 & 2.35 & 0.05 & 1.61 & 0.72 & 101.07 \\
\hline F3G1T-3 & 0.01 & 0.33 & 0.95 & 0.32 & 5.01 & 13.75 & 1.05 & 0.22 & 30.13 & 28.68 & 3.33 & 12.77 & 2.60 & 0.00 & 1.83 & 0.53 & 101.50 \\
\hline F3G1T-4 & 0.00 & 0.30 & 0.78 & 0.37 & 3.85 & 13.41 & 1.15 & 0.23 & 30.94 & 30.20 & 3.28 & 13.00 & 2.50 & 0.00 & 1.85 & 0.73 & 102.60 \\
\hline F4G2T-1 & 0.01 & 1.24 & 1.08 & 0.17 & 4.25 & 12.95 & 1.50 & 0.34 & 28.99 & 31.11 & 2.97 & 12.34 & 2.34 & 0.02 & 1.86 & 0.70 & 101.87 \\
\hline F4G2T-2 & 0.03 & 0.57 & 1.05 & 0.22 & 4.76 & 12.39 & 1.51 & 0.25 & 28.69 & 31.17 & 3.13 & 12.59 & 2.58 & 0.00 & 2.14 & 0.85 & 101.91 \\
\hline F4G2T-3 & 0.00 & 0.98 & 1.18 & 0.17 & 4.78 & 12.29 & 1.14 & 0.35 & 29.43 & 31.27 & 3.14 & 12.68 & 2.38 & 0.02 & 1.78 & 0.90 & 102.48 \\
\hline F4G2T-4 & 0.00 & 1.17 & 1.19 & 0.15 & 4.46 & 13.02 & 1.34 & 0.22 & 28.27 & 30.88 & 3.19 & 12.15 & 2.18 & 0.01 & 1.61 & 0.80 & 100.63 \\
\hline F5G1T-1 & 0.01 & 0.42 & 1.44 & 0.24 & 5.69 & 12.96 & 1.48 & 0.14 & 28.75 & 30.63 & 3.22 & 12.64 & 2.35 & 0.00 & 1.78 & 0.90 & 102.64 \\
\hline F5G1T-2 & 0.00 & 0.44 & 1.16 & 0.29 & 5.98 & 11.97 & 2.16 & 0.27 & 27.63 & 30.82 & 3.24 & 11.74 & 2.16 & 0.05 & 1.70 & 0.85 & 100.47 \\
\hline F5G1T-3 & 0.00 & 0.48 & 1.11 & 0.20 & 5.43 & 14.02 & 0.83 & 0.15 & 29.40 & 29.95 & 3.39 & 12.83 & 2.33 & 0.01 & 1.48 & 0.57 & 102.18 \\
\hline F5G1T-4 & 0.00 & 0.50 & 1.14 & 0.30 & 5.53 & 13.49 & 1.55 & 0.22 & 28.37 & 29.09 & 3.26 & 12.46 & 2.32 & 0.04 & 1.72 & 0.89 & 100.86 \\
\hline F6G1T-1 & 0.01 & 0.30 & 1.47 & 1.24 & 11.80 & 12.37 & 0.54 & 0.43 & 26.22 & 29.04 & 2.90 & 10.95 & 2.12 & 0.04 & 1.09 & 0.25 & 100.74 \\
\hline F6G1T-2 & 0.00 & 0.40 & 1.52 & 1.25 & 11.93 & 12.31 & 0.51 & 0.46 & 26.23 & 28.97 & 2.96 & 11.43 & 1.98 & 0.01 & 1.09 & 0.34 & 101.37 \\
\hline F6G1T-3 & 0.01 & 0.42 & 1.63 & 1.26 & 12.73 & 11.91 & 0.53 & 0.57 & 26.30 & 29.08 & 2.68 & 11.22 & 2.08 & 0.03 & 1.10 & 0.32 & 101.86 \\
\hline F7G1-T1 & 0.01 & 0.00 & 1.30 & 0.64 & 5.98 & 12.98 & 0.06 & 0.21 & 30.77 & 28.06 & 3.27 & 14.21 & 2.15 & 0.01 & 0.79 & 0.05 & 100.51 \\
\hline F7G1-T2 & 0.02 & 0.05 & 1.33 & 0.53 & 5.87 & 12.93 & 0.05 & 0.20 & 31.29 & 28.52 & 3.57 & 13.07 & 2.19 & 0.03 & 0.91 & 0.00 & 100.56 \\
\hline F7G1-T3 & 0.00 & 0.07 & 1.19 & 0.64 & 5.88 & 13.08 & 0.05 & 0.21 & 31.79 & 28.64 & 3.35 & 13.96 & 2.02 & 0.00 & 0.80 & 0.05 & 101.73 \\
\hline F7G1-T4 & 0.01 & 0.07 & 1.19 & 0.49 & 5.57 & 13.56 & 0.05 & 0.20 & 31.06 & 28.40 & 3.61 & 13.83 & 2.24 & 0.02 & 0.75 & 0.08 & 101.12 \\
\hline
\end{tabular}

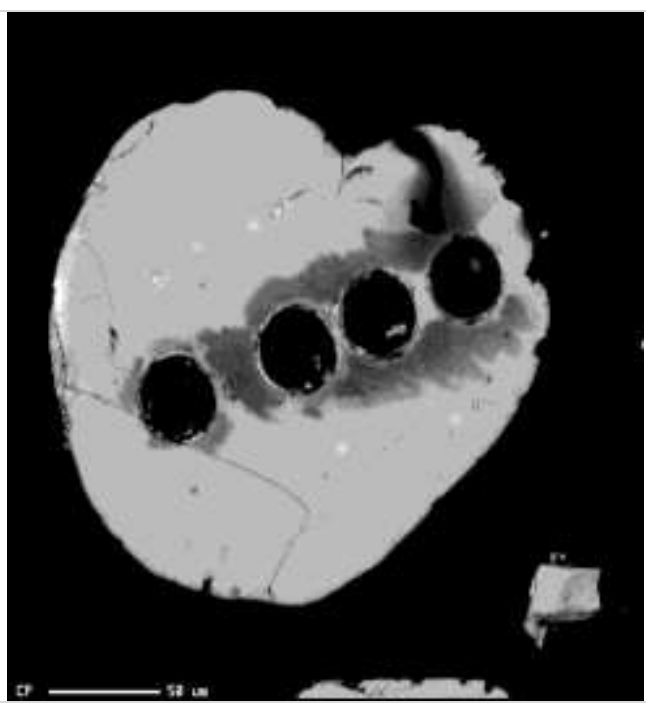

Amostra F2G1T-1-2-3

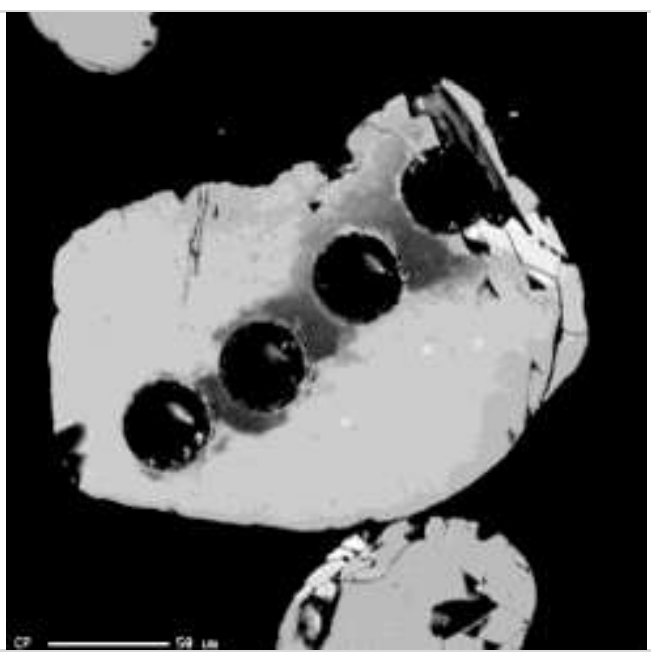

Amostra F3G1T-1-2-3-4

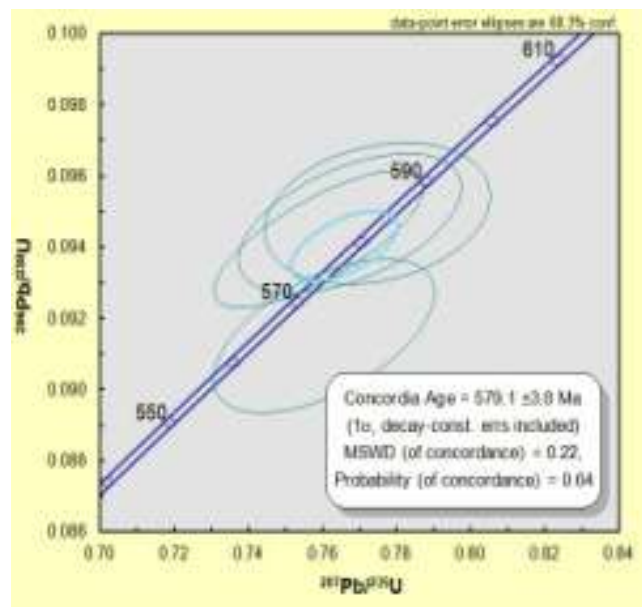

$579.1 \pm 3.8 \mathrm{Ma}$

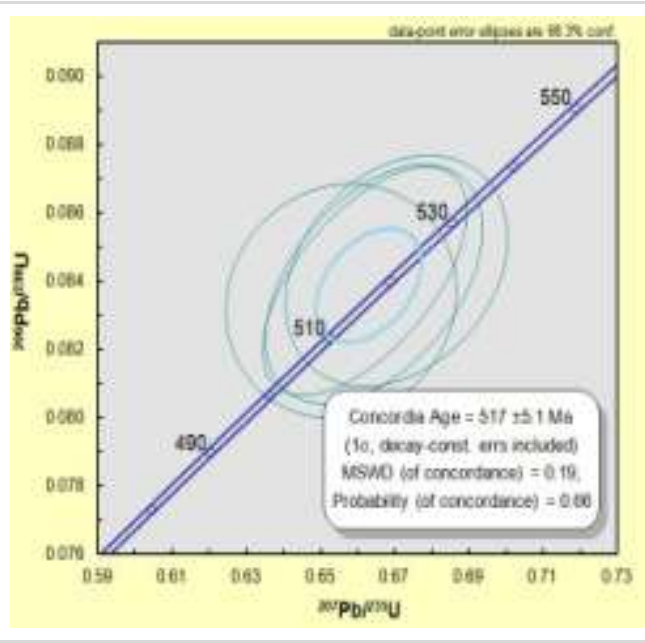

$517 \pm 5.1 \mathrm{Ma}$

Figura $2 a$ - Imagens por elétrons retroespalhados (microssonda eletrônica) dos grãos de monazita analisados e respectivos diagramas de idade de Concórdia com razões isotópicas ${ }^{206} \mathrm{~Pb} /{ }^{238} \mathrm{U}$ versus ${ }^{207} \mathrm{~Pb} /{ }^{235} \mathrm{U}$ (LA-ICP-MS) (Ludwig, 2003). O aspecto fraturado dos grãos se deve ao polimento durante a preparação das seções polidas. 


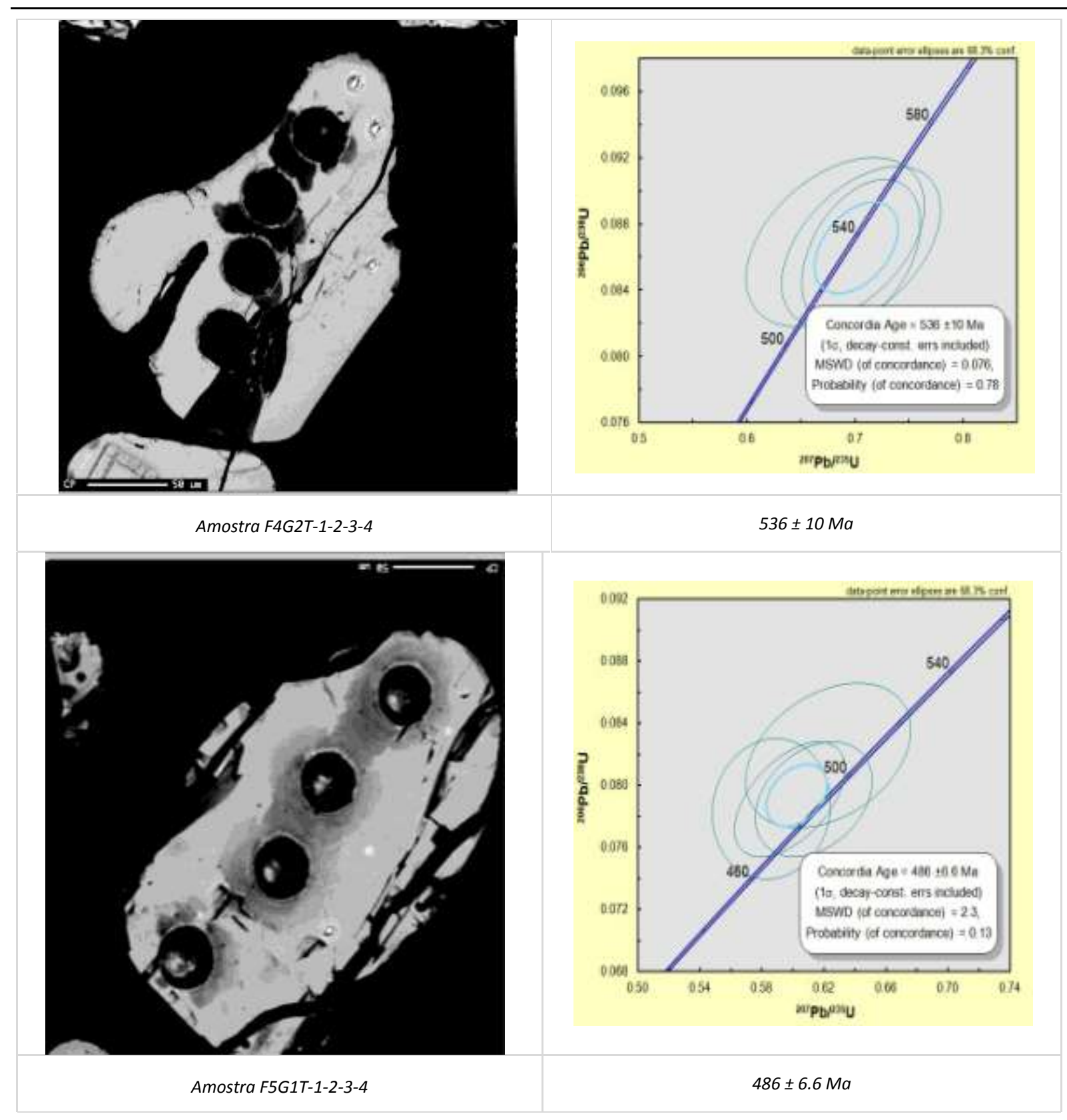

Figura $2 b$ - Imagens por elétrons retroespalhados (microssonda eletrônica) dos grãos de monazita analisados e respectivos diagramas de idade de Concórdia com razões isotópicas ${ }^{206} \mathrm{~Pb} /{ }^{238} \mathrm{U}$ versus ${ }^{207} \mathrm{~Pb} /{ }^{235} \mathrm{U}$ (LA-ICP-MS) (Ludwig, 2003). O aspecto fraturado dos grãos se deve ao polimento durante a preparação das seções polidas

\subsection{IDADES U-PB}

Foram obtidas razões isotópicas ${ }^{206} \mathrm{~Pb} /{ }^{238} \mathrm{U}$ versus ${ }^{207} \mathrm{~Pb} /{ }^{235} \mathrm{U}$ por LA-ICP-MS, segundo as condições analíticas da Tabela 2, nos seis grãos de monazita analisados por microssonda, cujos valores de idades $\mathrm{U}-\mathrm{Pb}$ estão contidos no intervalo entre $486 \mathrm{Ma}$ e $579 \mathrm{Ma}$, representados pelos diagramas de idade de Concórdia (Figuras 2a, 2b, 2c).

Uma feição interessante pode ser destacada pelo gráfico $\sum \mathrm{REE}+\mathrm{Y} 2 \mathrm{O} 3$ versus $\mathrm{CaO}+\mathrm{ThO}_{2}+\mathrm{UO}_{2}+\mathrm{PbO}$, no qual são mostradas idades calculadas com relação à composição de cada grão, destacando-se dois agrupamentos (Figura 3): um agrupamento de pontos (grãos F4G2, F5G1, F3G1, F7G1) relacionados com idades mais jovens, cuja composição se aproxima do membro monazita-(Ce) e um outro agrupamento em que as idades mais antigas correspondem aos grãos de monazita com tendência à composição cheralítica (grãos F2G1 e F6G1), onde ocorre um enriquecimento principalmente em $\mathrm{CaO}$ e $\mathrm{ThO}_{2}$. 


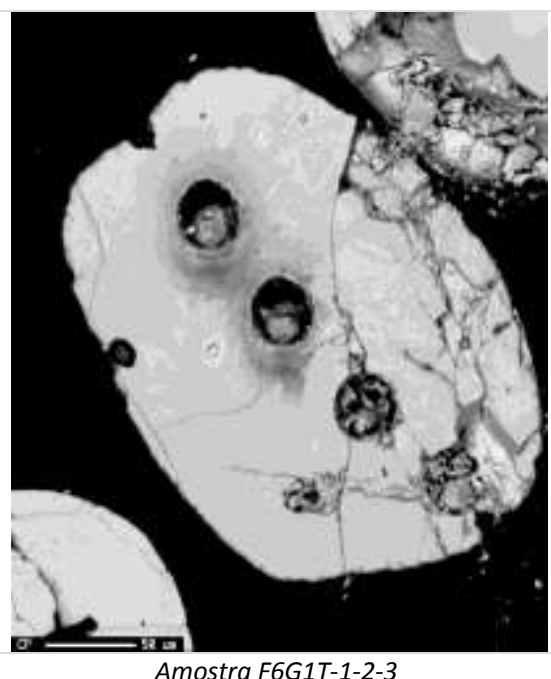

Amostra F6G1T-1-2-3

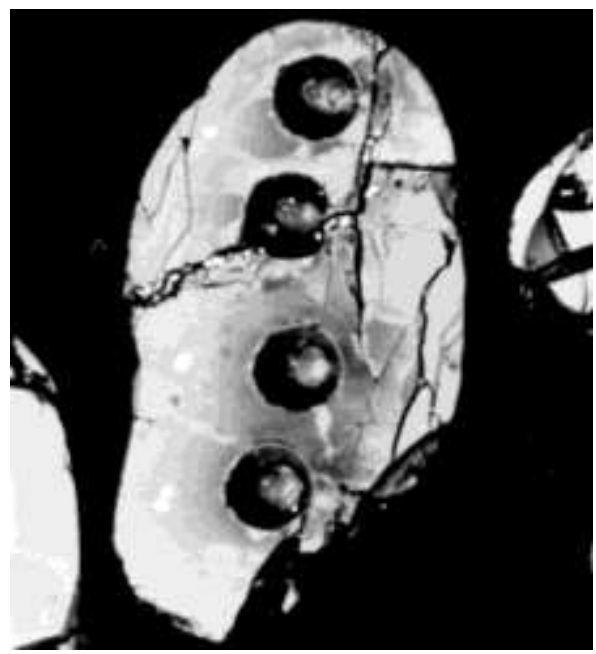

Amostra F7G1T-1-2-3-4

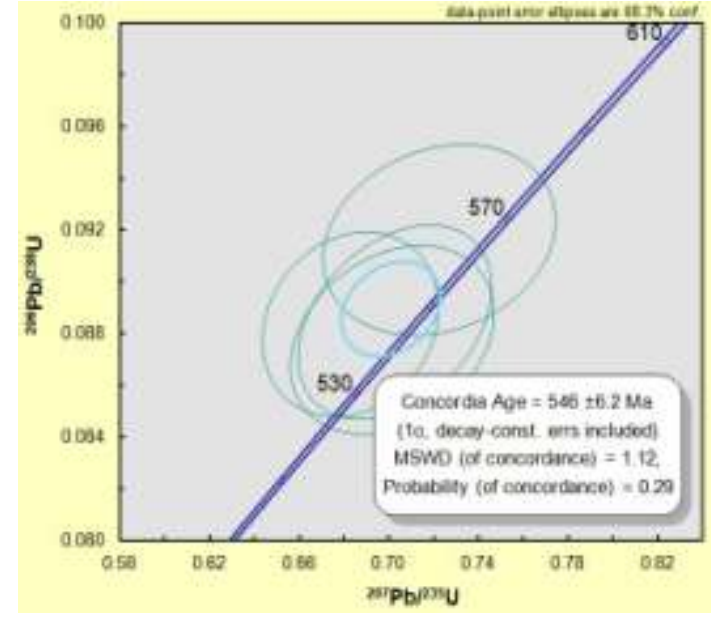

$546 \pm 6.2 \mathrm{Ma}$

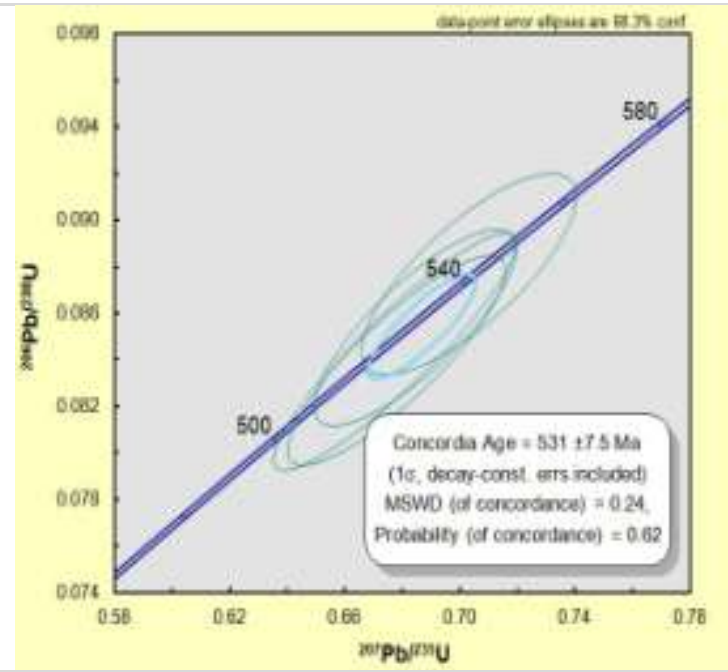

$531 \pm 7.5 \mathrm{Ma}$

Figura 2 c-: Imagens por elétrons retroespalhados (microssonda eletrônica) dos grãos de monazita analisados e respectivos diagramas de idade de Concórdia com razões isotópicas ${ }^{206} \mathrm{~Pb} /{ }^{238} \mathrm{U}$ versus ${ }^{207} \mathrm{~Pb} /{ }^{235} \mathrm{U}$ (LA-ICP-MS) (Ludwig, 2003). O aspecto fraturado dos grãos se deve ao polimento durante a preparação das seções polidas.

Tabela 2 - Resultados U-Pb obtidos por Laser Ablation MC-ICP-MS em grãos de monazitas.

\begin{tabular}{|c|c|c|c|c|c|c|c|c|c|c|c|c|c|c|c|c|c|c|c|}
\hline \multirow[b]{2}{*}{ Amostra } & \multicolumn{9}{|c|}{ Stacey \& Kramers common $\mathrm{Pb}$ corrected ${ }^{207} / 206 \mathrm{~Pb}$ data } & \multicolumn{10}{|c|}{ 204-Common $\mathrm{Pb}$ corrected ${ }^{206} \mathrm{~Pb} /{ }^{238} \mathrm{U}$ and ${ }^{207} \mathrm{~Pb} /{ }^{235} \mathrm{U}$ data based on ${ }^{204} \mathrm{~Pb}$} \\
\hline & Age $7 / 6$ & $1 \sigma(\mathrm{Ma})$ & $2 \sigma(\mathrm{Ma})$ & Ratio $7 / 6$ & $1 \sigma(\%)$ & $2 \sigma(\%)$ & Age $6 / 8$ & $1 \sigma(\mathrm{Ma})$ & $2 \sigma(\mathrm{Ma})$ & Ratio $6 / 8^{\star}$ & $1 \sigma(\%)$ & $2 \sigma(\%)$ & Age $7 / 5$ & $1 \sigma(\mathrm{Ma})$ & $2 \sigma(\mathrm{Ma})$ & Ratio $7 / 5^{*}$ & $1 \sigma(\%)$ & $2 \sigma(\%)$ & (rho) \\
\hline F2G1T-1 & 563.1 & 9.5 & 9.5 & 0.05889 & 1.68 & 1.68 & 563.07 & 8.8 & 14.0 & 0.09127 & 1.56 & 2.49 & 557.5 & 14.4 & 20.4 & 0.73153 & 2.58 & 3.67 & 0.6 \\
\hline F2G1T-2 & 582.2 & 10.6 & 10.6 & 0.05941 & 1.82 & 1.82 & 581.79 & 8.0 & 12.8 & 0.09445 & 1.37 & 2.20 & 563.1 & 14.5 & 20.2 & 0.74114 & 2.58 & 3.58 & 0.5 \\
\hline F2G1T-3 & 579.9 & 9.6 & 10.0 & 0.05935 & 1.65 & 1.73 & 579.35 & 7.8 & 12.5 & 0.09403 & 1.35 & 2.16 & 560.3 & 13.8 & 19.7 & 0.73648 & 2.46 & 3.52 & 0.8 \\
\hline F3G1T-1 & 517.9 & 9.1 & 9.1 & 0.05769 & 1.76 & 1.76 & 519.23 & 14.3 & 21.0 & 0.08388 & 2.76 & 4.05 & 513.8 & 14.9 & 21.7 & 0.65873 & 2.91 & 4.21 & 0.5 \\
\hline F3G1T-3 & 515.0 & 11.1 & 13.5 & 0.05761 & 2.16 & 2.62 & 516.31 & 14.0 & 20.4 & 0.08339 & 2.71 & 3.94 & 508.9 & 15.9 & 23.1 & 0.65069 & 3.13 & 4.55 & 0.1 \\
\hline F3G1T-4 & 519.9 & 10.3 & 11.6 & 0.05774 & 1.98 & 2.23 & 521.31 & 13.8 & 20.0 & 0.08423 & 2.65 & 3.83 & 515.9 & 15.2 & 21.8 & 0.66214 & 2.94 & 4.23 & 0.3 \\
\hline F4G2T-1 & 531.1 & 17.0 & 25.7 & 0.05804 & 3.20 & 4.84 & 532.35 & 18.3 & 29.2 & 0.08609 & 3.43 & 5.49 & 532.4 & 27.2 & 44.5 & 0.68933 & 5.11 & 8.35 & 0.4 \\
\hline F4G2T-2 & 534.0 & 25.6 & 27.5 & 0.05811 & 4.80 & 5.16 & 535.11 & 19.8 & 31.7 & 0.08655 & 3.70 & 5.91 & 538.9 & 37.1 & 51.4 & 0.70016 & 6.89 & 9.54 & 0.5 \\
\hline F4G2T-3 & 537.5 & 33.6 & 57.2 & 0.05821 & 6.25 & 10.64 & 537.03 & 20.9 & 33.4 & 0.08688 & 3.89 & 6.23 & 526.3 & 42.1 & 71.1 & 0.67918 & 8.01 & 13.51 & 0.4 \\
\hline F4G2T-4 & 544.9 & 31.8 & 45.8 & 0.05840 & 5.83 & 8.40 & 543.51 & 18.2 & 29.1 & 0.08797 & 3.35 & 5.36 & 481.9 & 33.7 & 50.6 & 0.60733 & 7.00 & 10.49 & 0.1 \\
\hline F5G1T-1 & 485.3 & 12.1 & 24.0 & 0.05684 & 2.49 & 4.95 & 486.80 & 18.6 & 31.5 & 0.07844 & 3.81 & 6.47 & 464.5 & 20.0 & 37.4 & 0.58010 & 4.30 & 8.04 & 0.1 \\
\hline F5G1T-2 & 488.9 & 9.5 & 10.1 & 0.05693 & 1.93 & 2.06 & 490.40 & 15.2 & 24.3 & 0.07904 & 3.10 & 4.96 & 473.0 & 18.6 & 31.0 & 0.59331 & 3.94 & 6.55 & 0.5 \\
\hline F5G1T-3 & 488.4 & 9.8 & 21.2 & 0.05692 & 2.01 & 4.33 & 490.36 & 15.2 & 24.3 & 0.07904 & 3.09 & 4.95 & 482.1 & 19.6 & 36.8 & 0.60768 & 4.06 & 7.64 & 0.3 \\
\hline F5G1T-4 & 505.3 & 22.6 & 35.9 & 0.05736 & 4.47 & 7.10 & 507.15 & 19.1 & 32.4 & 0.08185 & 3.76 & 6.38 & 486.8 & 27.5 & 46.1 & 0.61517 & 5.65 & 9.46 & 0.4 \\
\hline F6G1T-1 & 544.4 & 9.6 & 9.6 & 0.05839 & 1.77 & 1.77 & 545.18 & 14.6 & 23.4 & 0.08825 & 2.68 & 4.28 & 520.2 & 19.8 & 30.0 & 0.66917 & 3.80 & 5.77 & 0.2 \\
\hline F6G1T-2 & 544.8 & 10.6 & 23.3 & 0.05840 & 1.94 & 4.27 & 545.63 & 15.3 & 24.5 & 0.08833 & 2.81 & 4.49 & 532.0 & 21.6 & 37.1 & 0.68869 & 4.06 & 6.97 & 0.4 \\
\hline F6G1T-3 & 540.7 & 14.7 & 20.9 & 0.05829 & 2.72 & 3.86 & 541.47 & 14.8 & 23.7 & 0.08762 & 2.74 & 4.38 & 531.0 & 22.6 & 35.7 & 0.68709 & 4.26 & 6.73 & 0.3 \\
\hline F7G1-T1 & 518.1 & 9.2 & 10.9 & 0.05769 & 1.78 & 2.11 & 518.56 & 20.7 & 33.6 & 0.08377 & 3.99 & 6.48 & 488.3 & $\begin{array}{ll}19.8 \\
\end{array}$ & $\begin{array}{l}32.4 \\
\end{array}$ & 0.60954 & 4.10 & 6.71 & 0.9 \\
\hline F7G1-T2 & 515.7 & 9.5 & 11.6 & 0.05763 & 1.85 & 2.24 & 516.66 & 18.3 & 30.8 & 0.08345 & 3.54 & 5.96 & 486.2 & 18.0 & 30.4 & 0.61418 & 3.71 & 6.25 & 0.9 \\
\hline F7G1-T3 & 524.4 & 9.2 & 10.2 & 0.05786 & 1.75 & 1.94 & 524.86 & 17.1 & 28.8 & 0.08483 & 3.26 & 5.49 & 488.7 & 16.5 & 27.8 & 0.61811 & 3.39 & 5.69 & 0.8 \\
\hline F7G1-T4 & 538.2 & 10.6 & 11.9 & 0.05822 & 1.97 & 2.22 & 538.96 & 17.6 & 30.4 & 0.08720 & 3.26 & 5.64 & 505.8 & 17.7 & 30.0 & 0.64572 & 3.51 & 5.94 & 0.8 \\
\hline
\end{tabular}

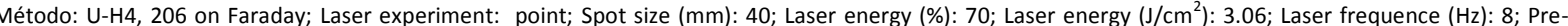
ablation: no; Flux $\mathrm{Ar}(\mathrm{L} / \mathrm{min})$ : 0.84; Flux He (L/min): 0.40; Data reduction: version 9a. 206 on L4; release 25.10.09. Rho: error correlation defined as err ${ }^{206} \mathrm{~Pb} /{ }^{238} \mathrm{U} / \mathrm{err}{ }^{207} \mathrm{~Pb} /{ }^{235} \mathrm{U}$. Laser Ablation MC-ICP-MS Neptune, Laboratório de Estudos Geocronológicos, Geodinâmicos e Ambientais, Instituto de Geociências UnB. 


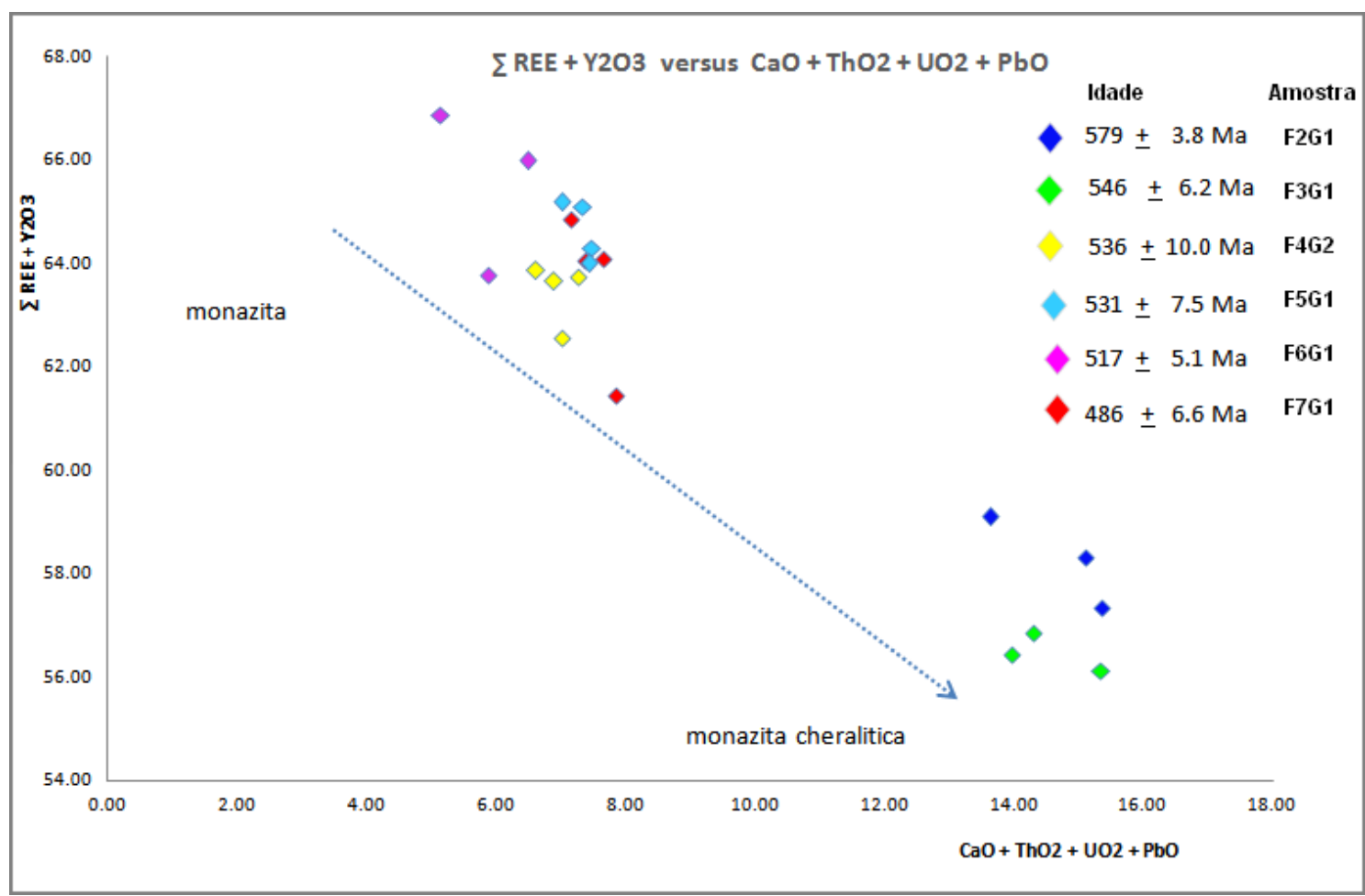

Figura 3 - Composição e idade dos grãos composicionalmente homogêneos lançados em gráfico de $\quad \mathrm{REE}+\mathrm{Y} 2 \mathrm{O} 3$ versus $\mathrm{CaO}+\mathrm{ThO}^{2}+\cup \mathrm{O}^{2}+\mathrm{PbO}$, com os furos do LA-ICP-MS.

\section{CONCLUSÕES}

Comparando-se as idades U-Pb obtidas via LAICP-MS, com as informações do mapa geológico regional da figura 1 , podem ser elaboradas as seguintes hipóteses sobre as possíveis áreas fontes dos grãos de monazita: as suítes G2 e G3 como rochas-fonte das monazitas mais antigas, suítes estas relacionadas com 0 arco sin-colisional desenvolvido simultaneamente ao metamorfismo e à deformação regional neoproterozóica. Já as monazitas mais jovens podem ser provenientes dos plútons graníticos das suítes G4 e G5, representantes das fases pós-colisionais.

\section{AGRADECIMENTOS}

Os autores expressam profunda gratidão pelos ensinamentos recebidos durante a convivência com o orientador inicial desta pesquisa, Prof. Dr. José Marques Correia Neves (in memoriam). Agradecemos também à equipe do Laboratório de Microanálises - UFMG, em especial ao geólogo Luis Garcia. M.L.S. Chaves agradece ao CNPq, pela concessão de Bolsa de Produtividade em Pesquisa.

\section{REFERÊNCIAS BIBLIOGRÁFICAS}

Albarède F., Telouk P., Blichert-Toft J., Boyet M., Agranier A., Nelson B. 2004. Precise and accurate isotopic measurements using multiple-collector ICPMS. Geochimica et Cosmochimica Acta, 68:2725-2744.

Bühn B., Pimentel M.M., Matteini M., Dantas E.L. 2009. High spatial resolution analysis of $\mathrm{Pb}$ and $U$ isotopes for geochronology by laser ablation multi-collector inductively coupled plasma mass spectrometry (LA-MC-ICP-MS). Anais da Academia Brasileira de Ciências, 81:99-114.

Fontanelli P. de R., De Ros L. F., Remus M.V.D. 2009. Provenance of deep-water reservoir sandstones from the Jubarte oil field, Campos basin, eastern Brazilian margin. Marine and Petroleum Geology, 26:1274-1298.

INB - INDÚSTRIAS NUCLEARES DO BRASIL 2012. Disponível em http://www.inb.gov.br/pt-

$\mathrm{br} /$ WebForms/interna.aspx?secao_id=96. Acessado junho 2012.

Jackson S.E., Pearson N.J., Griffin W.L., Belousova E.A. 2004. The application of laser ablation inductively coupled plasma mass spectrometry to in situ U-Pb zircon geochronology. Chemical Geology, 211: 47-69.

Jarosewich 2002. Smithsonian Microbeam Standards. Disponível em

http://mineralsciences.si.edu/facilities/standards.htm. Acessado em novembro 2012.

Kerpe, E. 2003. Caracterização Mineralógica dos Minerais Densos de Areias Monazíticas da Região de Buena, RJ. Dissertação de Mestrado, Escola de Engenharia, Universidade Federal de Minas Gerais, Belo Horizonte, 91 p.

Linthout, K. 2007. Tripartite division of the system $2 \mathrm{REEPO}_{4}-$ $\mathrm{CaTh}\left(\mathrm{PO}_{4}\right)_{2}-2 \mathrm{ThSiO}_{4}$, discreditation of brabantite, and recognition of cheralite as the name for members dominated by CaTh $\left(\mathrm{PO}_{4}\right)_{2}$. Canadian Mineralogist, 45:503-508.

Ludwig, K. R. 2003. Isoplot/Ex 3.00: A geochronological toolkit for Microsoft Excel. Berkeley Geochronology Center, Special Publication, n.4, 70 p.

Martim, L., Suguio, K., Dominguez, J. M. L., Flexor, J-M. 1997. Geologia do quaternário costeiro do litoral norte do Rio de Janeiro e do Espírito Santo. Publicações Especiais do Serviço Geológico do Brasil, Belo Horizonte, CPRM, 112p.

Pedrosa-Soares, A.C., Noce, C.M., Alkmim, F. F., Silva, L.C. da, Babinski, M., Cordani, U., Castañeda, C. 2007. Orógeno 
Araçuaí: síntese do conhecimento 30 anos após Almeida 1977. Geonomos, 15:1-16.

Stacey, J.S. \& Kramers, J.D. 1975. Approximation of terrestrial lead isotope evolution by a two-stage model. Earth and Planetary Science Letters, 26:207-221.

Suguio, K. 1998. Dicionário de geologia sedimentar e áreas afins. Bertrand Brasil, 1222pp.
Vlach, S. R. F. 2010. Th-U-Pb T $_{\top}$ Dating by electron probe microanalysis, part I. Monazite: Analytical procedures and data treatment. Revista do Instituto de Geociências, Geol. USP, Série Científica, São Paulo, 10:61-85.

Williams, M. L., Jercinovic, M. J., Hetherington, C. J. 2007. Microprobe monazite geochronology: understanding geologic processes by integrating composition and chronology. Annual Review of Earth and Planetary Science, 35:137-175. 